ИЗВЕСТИЯ АҚАДЕМИИ НАУК ЭСТОНСКОП ССР. ФИЗИКА * МАТЕМАТИКА

PROCEEDINGS OF THE ACADEMY OF SCIENCES OF THE ESTONIAN SSR. PHYSICS * MATHEMATICS

$1988,37, \quad 2$

\title{
DEPHASING OF OPTICAL IMPURITY STATES IN GLASSES: LOW-TEMPERATURE REGIME
}

\author{
(Presented by K. K. Rebane)
}

The dephasing of optical impurities in amorphous hosts is considered in the framework of a microscopic model. The dynamics of the disordered matrix is described by phonons and by an ensemble of two-level systems (TLSs), which are characteristic degrees of freedom of glasses. The TLSs are coupled to an impurity as well as to the matrix vibrations, which are considered a heat bath. A lineshape expression from linear response theory is evaluated for the cases of both a single TLS and many TLSs interancting with the impurity. It is found that the magnitude of experimental linewidths can be explained only if the latter situation is realized. At very low temperatures the linewidth increases $-T^{2.5}$, in the temperature range to follow $-T^{1.3}$ which is in agreement with experimental results. For the second temperature range several explanations of the temperature dependence of the optical dephasing rate are offered which are all compatible with the mathematical structure of the theory.

\section{Introduction}

Optical properties of impurities in glasses have been the subject of many experimental and theoretical investigations in recent years. Apart from possible applications of these materials in optical storage devices $\left[{ }^{1}\right]$, one hopes to obtain information on the still unknown nature of the two-level systems (TLS) $\left[{ }^{2,3}\right]$ which have been introduced to describe thermal and acoustic properties of glasses. For the investigation of this question in the optical regime, various experimental methods have been used such as fluorescence line narrowing $\left[{ }^{4-6}\right]$, photochemical (PHB) and non-photochemical (NPHB) hole-burning $\left[{ }^{7-15}\right]$, accumulated photon echoes $\left[{ }^{16,17}\right]$, and two-pulse photon echoes $\left[{ }^{16,18,19}\right]$. These experiments are carried out in order to probe the properties of the material on two different time scales, processes with very short times (e.g. $10^{-9} \mathrm{~s}$ ), which show up in the homogeneous optical linewidth, and processes on longer time scales (e.g. $1 \mathrm{~s}$ ) which give rise to time dependences in lineshapes and -widths.

In this paper we deal with the theory of the temperature dependence of the homogeneous optical linewidth and thus with short time processes. There has appeared a large number of papers on this problem in recent years. In $\left[{ }^{20-23}\right]$ the homogeneous linewidth has been calculated on the basis of a spectral diffusion model $\left[{ }^{24}\right]$. Other treatments are based on the TLSs interacting with acoustic $\left[{ }^{25-30}\right]$ or optical phonons/librons $\left[{ }^{31}\right]$ or fractons $\left[{ }^{32}\right]$, or on additional relaxation mechanisms which are caused by the direct interaction of the impurity with librational modes $\left[{ }^{33}\right]$. Finally, the linewidth has also been assumed to originate from Raman processes $\left[{ }^{34,35}\right]$, or being caused by tunnelons $\left[{ }^{36}\right]$. 
Fig. 1 (top) gives a schematic picture of the optical absorption spectrum of impurities in glasses. Its basic feature is the large inhomogeneous width which in organic glasses may achieve values up to several hundreds of $\mathrm{cm}^{-1}$. This inhomogeneous line is composed of many homoge-

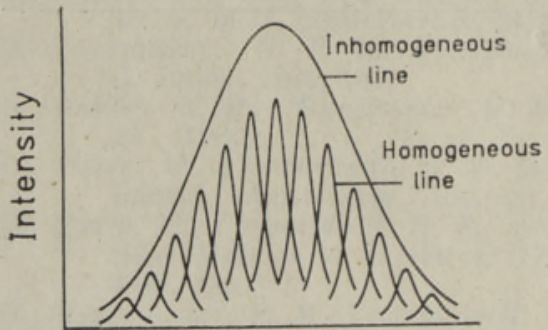
neous contributions stemming from the various inequivalent impurity sites in the glass. The experimental results show that the width of the homogeneous contributions is usually larger in glasses than in crystals. It is proportional to $T^{\alpha}$ in the former materials with $1 \leqslant \alpha \leqslant 2$; in several measurements a $T^{1.3}$ dependence is obtained, whereas for impurities in

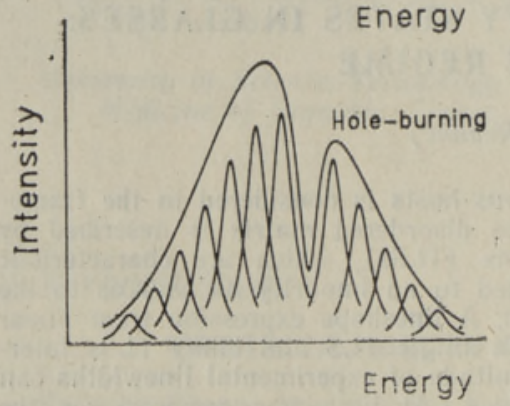
crystals the linewidth is $\propto T^{7}$. The lower part of the figure illustrates the measurements of the homogeneous linewidth via hole burning.

Fig. 1. Top: Inhomogeneous spectrum originating from homogeneous lines with different central frequencies. Bottom: Change of the spectrum through hole burning.

\section{The model}

In order to describe the unusual magnitude and temperature dependence of the homogeneous linewidth, we assume that at low temperatures typical degrees of freedom of glasses, the TLSs, play a dominant role in the line broadening mechanism. A schematic representation of the model is given in Fig. 2. The impurity is characterized by the two energy levels which are relevant for the optical transition. It is coupled to the TLSs of the glass; in the figure only a single TLS is drawn for simplicity. Finally, the TLSs are coupled to the phonons of the glass, which is described as a heat bath.

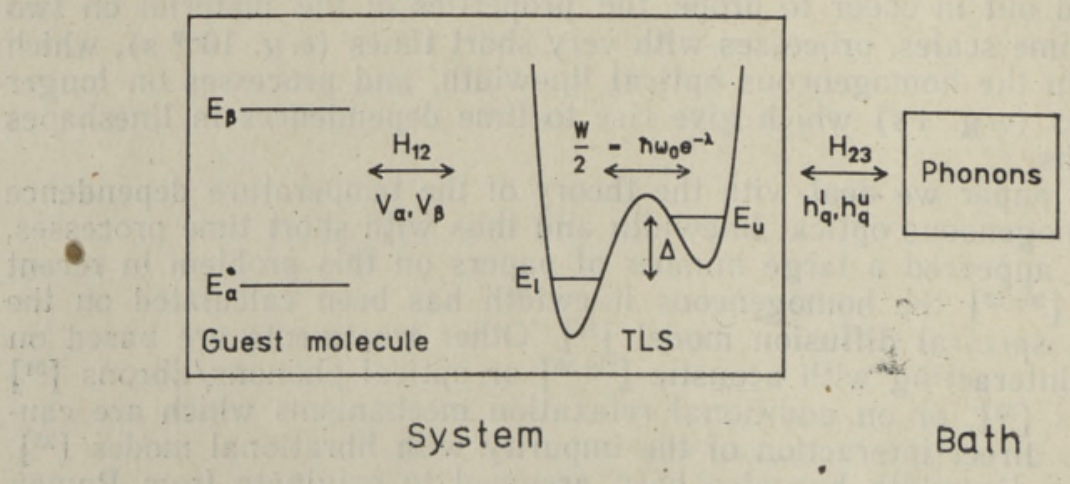

Fig. 2. The components of the model and their interactions. 
The Hamiltonian of the model is given by $\left[{ }^{27-30}\right]$

where $(\hbar=1)$

$$
H=H_{1}+H_{12}+H_{2}+H_{23}+H_{3},
$$

$$
\begin{aligned}
& H_{12}=\sum_{\rho, k, n}|\varrho\rangle\langle\varrho|\left\{\left(S_{\rho}^{k}-(-1)^{n} V_{\rho}^{k} \frac{\Delta^{k}}{E^{k}}\right)\left|\psi_{n}^{k}\right\rangle\left\langle\psi_{n}^{k}\right|+\right. \\
& \left.+V_{\rho}^{k} \frac{W^{k}}{E^{k}}\left|\psi_{n}^{k}\right\rangle\left\langle\psi_{\tilde{n}}^{k}\right|\right\}, \\
& H_{3}=\sum_{\mathbf{q}} \omega_{\mathbf{q}} b_{\mathrm{q}}^{+} b_{q}, \quad(\mathbf{q}=(\underline{\mathrm{q}}, \sigma)), \\
& H_{23}=\sum_{\mathrm{q}} \sum_{k, n}\left\{(-1)^{n+1} D_{\mathrm{q}}^{k} \frac{\Delta^{k}}{E^{k}}\left|\psi_{n}^{k}\right\rangle\left\langle\psi_{n}^{k}\right|+\right. \\
& \left.+D_{\mathrm{q}}^{k} \frac{W^{k}}{E^{h}}\left|\psi_{n}^{k}\right\rangle\left\langle\psi_{\tilde{n}}^{k}\right|\right\} \cdot\left(b_{\mathrm{q}}+b_{-q}^{+}\right), \\
& D_{\mathrm{q} \sigma}^{k}=\frac{1}{2}\left(h_{\mathrm{q} \sigma}^{l(k)}-h_{\mathrm{q} \sigma}^{u(k)}\right), \\
& h_{\underline{q} \sigma}^{r(k)}=i \sqrt{\frac{\omega_{\mathrm{q} \sigma}}{2_{\mathrm{Q}} V c_{\sigma}^{2}}} \sqrt{\left.\omega_{\underline{q} \sigma} / \omega_{c}\right)^{k-1}} f_{\sigma}^{r(k)} .
\end{aligned}
$$

$H_{1}$ describes the states of the guest molecule with energy $E_{\alpha}$ and $E_{\beta}$. $H_{2}$ is the Hamiltonian of the TLSs. The sum runs over all TLSs in the glass. The important quantities in $\mathrm{H}_{2}$ for the following discussion are the asymmetry parameters $\Delta^{k}$ and the overlap parameters $\lambda^{k}$ (see Fig. 2). $H_{12}$ describes the interaction between the guest and the TLSs, the parameters $\Delta V^{k}=V_{\alpha}^{k}-V_{\beta}^{k}$ characterize the coupling strengths. $H_{3}$ is the Hamiltonian of the bath, $\mathrm{H}_{23}$ the interaction between the bath and the TLSs. Through this part of the Hamiltonian, the temperature is introduced. The quantities $D_{q}^{k}$ are the coupling matrix elements. They are proportional to the deformation potentials $f_{\sigma}^{r(k)}$ and, if $k=1$, to $\sqrt{\omega_{\mathrm{q}}}$. This square root dependence is well known from solid state theory for the interaction with acoustic phonons. $k$ has been introduced here as a phenomenological parameter which allows for three different physical interpretations which are given in the concluding remarks.

\section{Optical lineshape}

The optical lineshape is calculated within linear response theory. It is determined by the one-sided Fourier transform of the two-time correlation function of the optical dipole moment operator $p$ :

$$
\chi^{\prime \prime}(\omega)=\frac{1}{2} \int_{0}^{\infty} d \tau\left(e^{i \omega \tau}-e^{-i \omega \tau}\right) \operatorname{Tr}([p(\tau), p] \varrho) \text {. }
$$


The correlation function $\operatorname{Tr}([p(\tau), p] \varrho)$ is calculated on the basis of the Hamiltonian of the previous section using Mori's formalism and the usual approximations - the Markov and Born ones and the Debye model for the phonons.

For coupling of the guest molecule to a single TLS, the optical lineshape has been calculated exactly $\left[{ }^{30}\right]$. In this case the result obtained by S. K. Lyo $\left[{ }^{27}\right]$, using a Green's function technique, is basically equivalent to ours. The lineshape depends on the coupling strength $\Delta V$ between guest and TLS and on the parameters $\lambda$ and $\Delta$ characterizing the latter. The energy level scheme in Fig. 3 illustrates the situation.

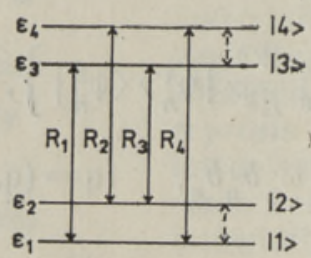

Fig. 3. Energy levels of a system consisting of one impurity and one TLS.

The narrow-band laser excitation selects specific impurities which are at resonance with the laser and which are coupled to TLSs whose $\lambda$ and $\Delta$ values are distributed according to the distribution of P. W. Anderson et al. $\left[{ }^{2}\right]$, and W. A. Phillips [ $\left.{ }^{3}\right]$. In an absorption experiment the various contributions are summed up. This sum is mathematically equivalent to a properly normalized average of the lineshape over the distribution on $\lambda$ and $\Delta$. The essential outcome $\left[{ }^{37,38}\right]$ of this lineshape calculation is a width of the order of $10^{-7} \omega_{D} \approx 10^{-5} \mathrm{~cm}^{-1}$ which is much smaller than the observed linewidth.

Therefore a model which couples the guest molecule to a single TLS is not appropriate and we have to consider the situation of an impurity coupled to many TLSs. The details of the calculation, which in addition to the aforementioned approximations employs a kind of a random phase approximation, are rather intricate $\left[{ }^{37}\right]$. The resulting lineshape expression is $\left[{ }^{30}\right]$ :

$$
\begin{aligned}
\chi^{\prime \prime}(\omega) & =\frac{4 v^{2}}{\prod_{k=1}^{N}\left(1+e^{-\beta \varepsilon_{\alpha}^{k}}\right)+\exp \left\{-\beta\left(E_{0}+\frac{1}{2} \sum_{k=1}^{N}\left(\varepsilon_{\beta}^{k}-\varepsilon_{\alpha}^{k}\right)\right)\right\} \prod_{k=1}^{N}\left(1+e^{-\beta \varepsilon_{\beta}^{k}}\right)} \times \\
& \times \sum_{n_{1}, m_{1}, n_{2}, \ldots m_{N}} \exp \left\{-\frac{1}{2} \beta \sum_{k=1}^{N}\left((-1)^{m_{k}}+1\right) \varepsilon_{\alpha}^{k}\right\}\left(1-e^{-\beta \varepsilon}\{j\}\right) \times \\
& \times \prod_{k=1}^{N}\left\{\delta_{n_{k}, m_{k}} \cos ^{2}\left(\beta_{k}-\alpha_{k}\right)+\left(1-\delta_{n_{k}, m_{k}}\right) \sin ^{2}\left(\beta_{k}-\alpha_{k}\right)\right\} \times \\
& \times \frac{\omega \varepsilon\{\mathbf{j}\} \varphi\{\mathbf{j}\}}{\left[\omega^{2}-(\varepsilon\{\mathbf{j}\})^{2}+(\varphi\{\mathbf{j}\})^{2}\right]^{2}+4(\varepsilon\{\mathbf{j}\} \varphi\{\mathbf{j}\})^{2}} .
\end{aligned}
$$

The expression in the first line represents the normalization of the lineshape, the second line is called thermal prefactor and describes thermal oecupation numbers. The third line, the trigonometric prefactor, results from the interaction between the impurity and the TLSs, and describes the mixing of their states. The last line is the shape factor, and can be represented as a difference of Lorentzians at positions $\pm \varepsilon\{\mathbf{j}\}$ and 
with widths $\varphi\{\mathbf{j}\}$. In Fig. 4 the result is visualized, again in terms of energy levels of the coupled impurity many-TLS system. The left part of the figure shows the situation in the case that all TLSs are identical, the right part - the case where the TLSs have different values $\Delta^{k}$ and $\lambda^{k}$ resulting in a rather broad distribution of the energy states.
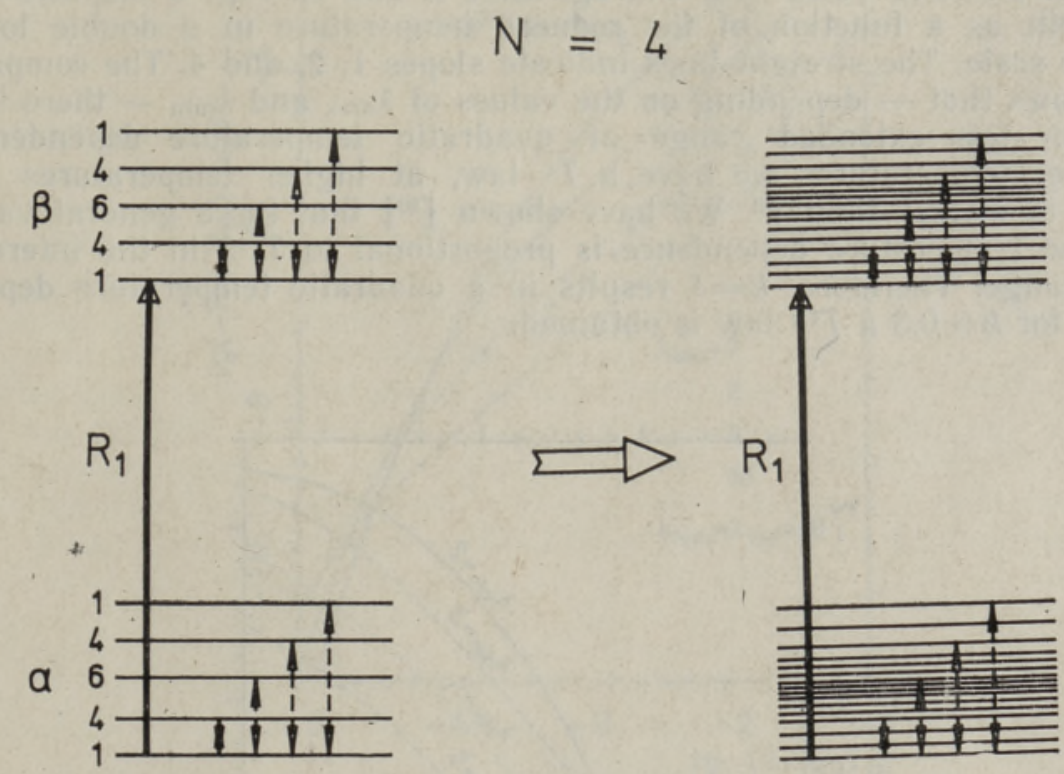

Fig. 4. Energy levels of a system of one impurity coupled to several - in the case displayed, four - TLSs. The left hand side corresponds to TLSs with identical energy splittings, and the degeneracies of the various levels are given.

From the many possible optical transitions between the lower and upper groups of energy levels which are all contained in the lineshape expression (10), we shall only consider the transition denoted by $R_{1}$ for the following reasons: first, at very low temperatures only the lowest energy level is occupied to a considerable extent, and second, the transition dipole moment between the ground and excited states is largest when the configuration of the TLSs does not change. On this condition the lineshape expression reduces to a single Lorentzian with a width $\left[{ }^{30}\right]$

$$
\varphi_{\mathrm{th}}=\sum_{k=1}^{N} \frac{\pi f^{2}}{8 \varrho V c^{2}} \sum_{\rho=\alpha}^{\beta}\left(\frac{\varepsilon_{\rho}^{k}}{\omega_{D}}\right)^{k-1} \varepsilon_{\rho}^{k} g_{D}\left(\varepsilon_{\rho}^{k}\right) n\left(\varepsilon_{\rho}^{k}\right)\left(B_{\rho}^{k}\right)^{2} .
$$

The sum over $k$ in this expression shows that the linewidth, i. e. the dephasing rate, is composed of contributions of all TLSs and depends on the parameters $\lambda^{k}, \Delta^{k}$ and $\Delta V^{k}$ describing the $k=$ th TLS and its interaction with the impurity. (The heuristic generalization of Lyo's linewidth expression to the case of coupling the impurity to many TLSs $\left[{ }^{27}\right]$ is different from (11) in that it contains terms which are similar to our thermal and trigonometric prefactors in the linewidth itself.) The sum in (11) is evaluated by replacing it with an integral over the distribution of TLS parameters $\widetilde{P}(\lambda, \Delta, \Delta V)$. Assuming that $\Delta V$ is independent of $\lambda$ and $\Delta$, the distribution factorizes $\widetilde{P}(\lambda, \Delta, \Delta V)=\bar{P}(\Delta V) \cdot P(\lambda, \Delta)$. Here, $P(\lambda, \Delta)$ is the distribution of P.W. Anderson et al. $\left[{ }^{2}\right]$ and W. A. Phillips $\left[{ }^{3}\right]$. The distribution $\bar{P}(\Delta V)$ for the interaction between impurity and TLS can be rather complicated. However, in the simplest case we may assume that it is determined by the dependence of $\Delta V$ on $r$, the distance between 
impurity and TLS. We shall take $\Delta V \propto 1 / r^{3}$, which corresponds to (electric or elastic) dipole-dipole interaction between guest and TLS, or $\Delta V \propto$ $\propto 1 / r^{4}$, in the case of quadrupole-dipole interaction. Assuming a homogeneous distribution of TLSs, we have $\bar{P}(r) \propto r^{2}$, which determines $\bar{P}(\Delta V)$.

Evaluating the average, we first replace the distribution of $\Delta V$ values with an effective value and average over $\lambda$ and $\Delta$. Fig. 5 displays the linewidth as a function of the reduced temperature in a double logarithmic scale. The straight lines indicate slopes 1,2 , and 4 . The comparison shows that - depending on the values of $\lambda_{\max }$ and $\lambda_{\min }$ - there is a more or less extended range of quadratic temperature dependence. At lower temperatures we have a $T^{4}$ law, at higher temperatures the ascent is weaker than $T^{2}$. We have shown $\left[{ }^{30}\right]$ that for a general value of $k$ the temperature dependence is proportional to $T^{1+k}$ in the intermediate range. Therefore, $k=1$ results in a quadratic tempęrature dependence, for $k=0.3$ a $T^{1.3}$ law is obtained.

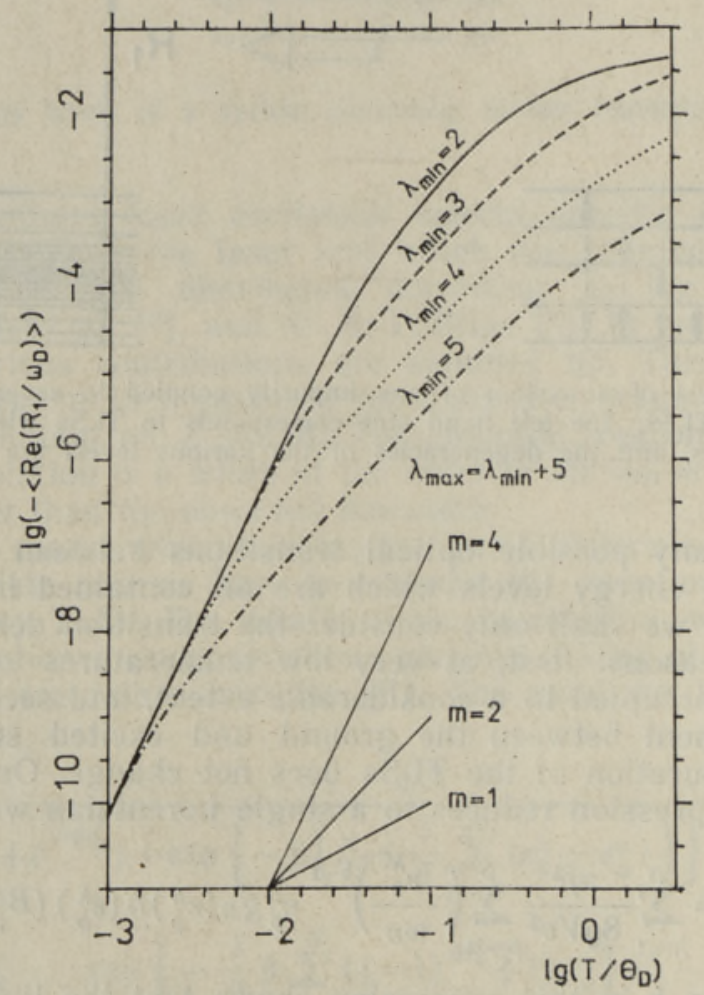

Fig. 5. Linewidth averaged with respect to $\Delta$ and $\lambda$. The $\lambda$ ranges used in the averages are indicated. The $\Delta$ range covers an interval of size $2.6 \omega_{D}$

Parameters: $\Delta V=0.3 \omega_{D}, \quad \theta_{D}=300 \mathrm{~K}$ (Debye temperature), $c=3 \mathrm{~km} / \mathrm{s}$ (velocity of sound), $Q=2 \mathrm{~g} / \mathrm{cm}^{3}, f=1 \mathrm{ev}$ (deformation potential).

Fig. 6 gives the linewidth for this value of $k$ and a set of different values of $\lambda_{\max }$ and $\lambda_{\min }$ together with experimental data of S. Völker et al. $\left[{ }^{39}\right]$ and J. Hegarty et al. $\left[{ }^{18}\right]$. We find rather good agreement between the slopes of the experimental and theoretical data. Although we have taken $\Delta V$ to be proportional to $1 / r^{3}$ in this calculation, we obtain the same temperature dependences as if we had assumed a single effective value for $\Delta V$. Why this is so, will become clear from the discussion of 


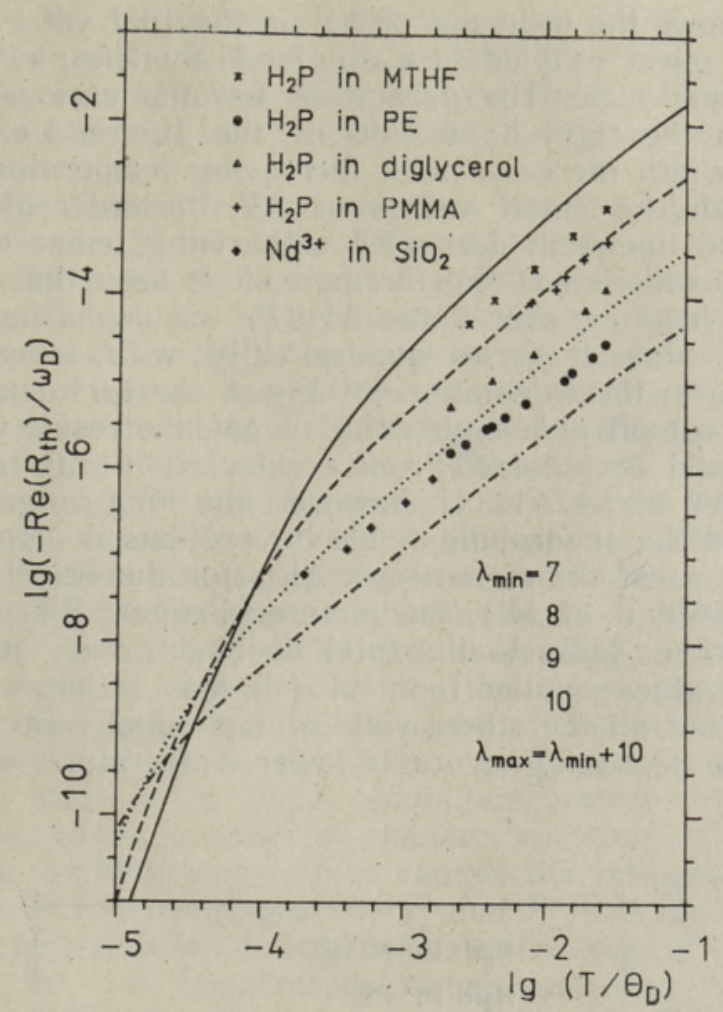

Fig. 6. Linewidth according to (11) in comparison with experimental data from [ $\left.{ }^{39}\right]$ and $\left[{ }^{18}\right]$. Short range interaction is assumed. The $\Delta$ range is over in interval of length $0.2 \omega_{D}$.

Parameter values: $\langle\Delta V\rangle=10^{-3} \omega_{D}, \Delta V_{\max }=0.1446 \omega_{D}, \Delta V \propto 1 / r^{3}, r_{\max }=10 r_{\min }, \theta_{D}=$ $=150 \mathrm{~K}, c=2 \mathrm{~km} / \mathrm{s}, \varrho=1 \mathrm{~g} / \mathrm{cm}^{3}, k=0.3, f=1 \mathrm{eV}$. ( $\mathrm{H}_{2} \mathrm{P}-$ free-base porphin; $M_{\text {in }}, \theta_{D}=$ 2-methyltetrahydrofuran; PMMA - polymethylmethacrylate; $\mathrm{PE}$ - polyethylene).
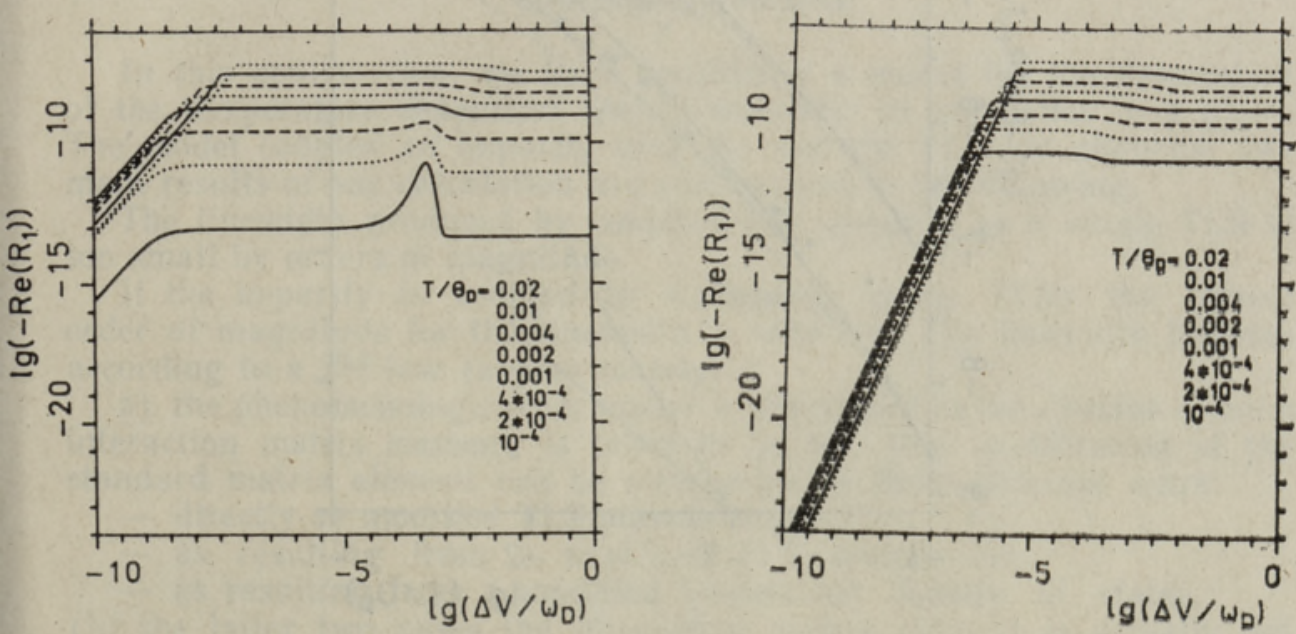

Fig. 7. Linewidth (in units of $\omega_{D}$ ) of the optical transition $R_{1}$ as a function of $\Delta V$. Parameter values: $\lambda=8, V^{\alpha}=0.6 \omega_{D}, \theta_{D}=300 \mathrm{~K}, c=3.75 \mathrm{~km} / \mathrm{s}, \varrho=2 \mathrm{~g} / \mathrm{cm}^{3}, f=1 \mathrm{eV}$. Left: $\Delta=2 V^{\alpha}$; the straight curve segments on the left hand side of the figure describe a $\Delta V^{4}$ law.

Right: $\Delta=2 V^{\alpha}+10^{-3} \omega_{D}$, to the left of their bends the curves-are proportional to $\Delta V^{2}$ 
Fig. 7, which shows the influence of $\Delta V$ on the (not yet average) dephasing rate for a guest coupled to a single TLS. The plot is again in a double logarithmic scale. The parameter for the various curves is the temperature. On the right hand side of the figure, i.e. for large $\Delta V$ values, the linewidth increases with increasing temperature, whereas on the left hand side, for small values of $\Delta V$, the order of the curves is reversed, i.e. the linewidth decreases with rising temperature, which is a motional narrowing effect. Furthermore, it is seen that for $\Delta V$ values larger than the bending over value $\Delta V_{c}(T)$ the dephasing rate is independent of $\Delta V$, while it varies quadratically with temperature below $\Delta V_{c}(T)$. Because in the calculation for Fig. 6 the $1 / r^{3}$ dependence of the interaction was cut off at a high value of $\Delta V$, the result was essentially the same as would be obtained from a calculation with a single «effective» value of $\Delta V$ above $\Delta V_{c}$. If, however, the long-range nature of the dipole-dipole and the quadrupole-dipole interactions is actually accounted for by avoiding a cut off at too high $\Delta V$ (for numerical reasons, it is impossible to avoid it at all), the picture changes. When the contributions of the various TLSs to the total dephasing rate are summed up, TLSs with $\Delta V$ values smaller than $\Delta V_{c}(T)$ may be neglected in a first approximation (but all the others yield almost equal contributions). Considering now the dephasing rate at a lower temperature, we have to sum

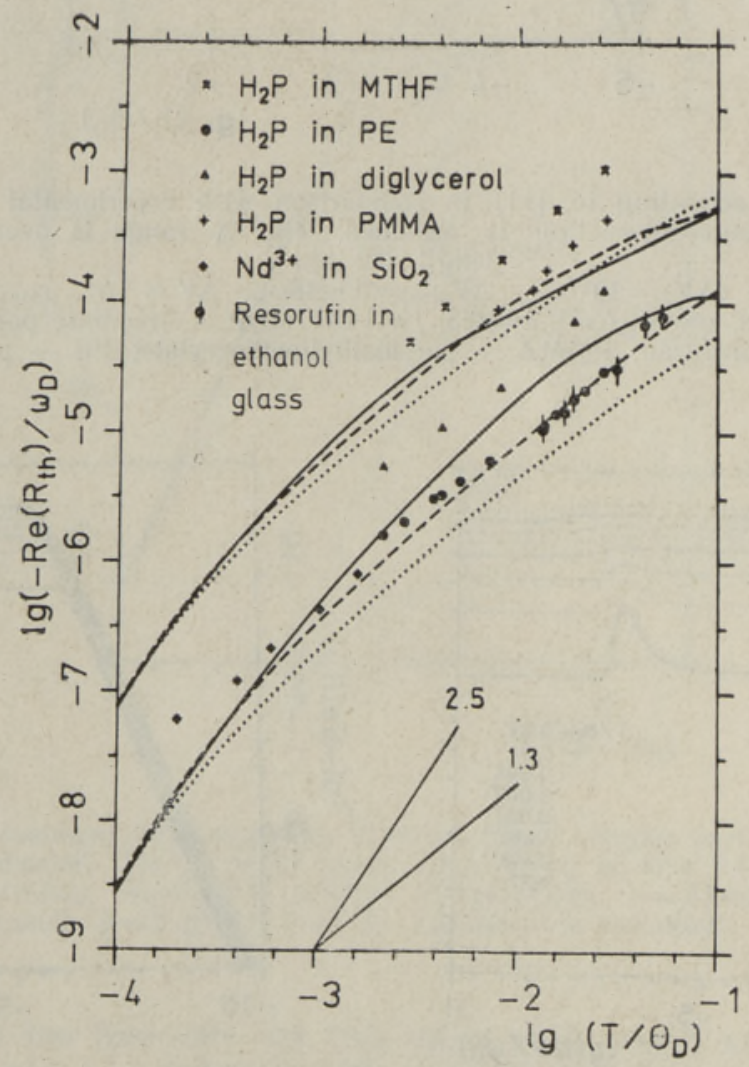

Fig. 8. Linewidth in comparison with experimental data. The long-range nature of the interaction is taken into account. The $\Delta$ range covers an interval of length $0.2 \omega_{D}$.

Parameter values: $\Delta V_{\max }=0.72383 \times 10^{-3} \omega_{D}=10^{6} \Delta V_{\min }\left(\rightarrow\langle\Delta V\rangle=10^{-8} \omega_{D}\right.$ for the upper curves), $\theta_{D}=200 \mathrm{~K}, c=2 \mathrm{~km} / \mathrm{s}, \varrho=2 \mathrm{~g} / \mathrm{cm}^{3}, k=1.0, f=1 \mathrm{eV}$.

Full lines: $\lambda_{\min }=6$, dashed lines: $\lambda_{\min }=7$, dotted lines: $\lambda_{\min }=8 ; \lambda_{\max }=\lambda_{\min }+7$. Upper curves: $\Delta V \propto 1 / r^{3}$, lower curves: $\Delta V \propto 1 / r^{4}$. 
up all TLSs with $\Delta V$ values down to a new value $\Delta V_{c}(T)$, which is smaller than the previous one. This means that more TLSs contribute to the dephasing rate at lower temperatures. These additional TLSs cause the linewidth to decrease less quickly than it does according to a quadratic power law, even at $k=1$.

In Fig. 8, the linewidth is shown as a function of temperature when the summation over TLSs with different values of $\Delta V$, i. e. different distances from the guest, is carried out (up to sufficiently large distances or down to small enough $\Delta V$ values). The upper curves correspond to dipole-dipole interaction, the lower ones to quadrupole-dipole interaction. The two groups of curves are shifted against each other because in the second case a lower number of TLSs has been taken into account. (The ratio $\Delta V_{\max } / \Delta V_{\min }$ is the same, viz. $10^{6}$, for both groups.) The two straight lines indicate $T^{2.5}$ and $T^{1.3}$ power laws. Thus for the lowest temperatures shown, the linewidth is $\sim T^{2.5}$ followed by a temperature range with linewidth $\sim T^{1.3}$. For higher temperatures the ascent of the width is still weaker. In the first range the increase of the linewidth with increasing temperature is determined by the increasing number of phonons available at a certain irequency and by the increasing number of TLSs contributing to the dephasing. In the second temperature range all TLSs (for given parameters of the distribution on $\lambda$ and $\Delta$ ) contribute to the dephasing. The slope of the width versus temperature curve is then given solely by the increasing number of phonons and thus smaller than in the previous range. In both temperature ranges the influence of the shift of $\Delta V_{c}(T)$ results in a weakening of the $T^{4}$ and $T^{2}$ laws shown in Fig. 5 . The still weaker ascent in the third range indicates the onset of motional narrowing. However, in this temperature range probably other mechanisms (e.g. spectral diffusion, Raman processes) dominate the linewidth. Furthermore, the figure shows experimental data of S. Völker et al. [ $\left.{ }^{39}\right]$, J. Hegarty et al. $\left[{ }^{18}\right]$, and low temperature data of Fayer et al. $\left[{ }^{40}\right]$. The agreement between theory and experiment is not as good as in that of Fig. 6, but in the present case no parameter had to be fitted.

\section{Concluding remarks}

In this contribution, we have considered a model for the description of the temperature dependent optical linewidth of impurities in a glass. The model couples an impurity to TLSs and the TLSs to phonons. The main results of our calculation are summarized in the following.

The linewidth produced by coupling the impurity to a single TLS is too small by orders of magnitude.

If the impurity is coupled to sufficiently many TLSs, the correct order of magnitude for the linewidth is obtained. The linewidth behaves according to a $T^{1.3}$ law (approximately) if

a) the phenomenological parameter $k$, introduced in the electron-phonon interaction matrix element, is taken to be 0.3 . This modification of the standard matrix element can be interpreted in three different ways:

- directly as modified TLS-phonon interaction,

- as resulting from a modified TLS distribution,

- as resulting from a modified vibrational density of states.

(In the latter two cases the interaction matrix element is actually not changed, but the modifications of the two other quantities can be mapped on an effective modified matrix element.)

b) the impurity-TLS interaction $\Delta V$ is distance dependent and long range. Both dipole-dipole interaction and quadrupole-dipole interaction can produce temperature dependences close to $T^{1.3}$. 
We showed that the temperature dependence of the linewidth obtained from our calculation agrees with hole burning $\left[{ }^{39}\right]$ and photon-echo $\left[{ }^{18}\right]$ measurements. It is also consistent with the non-exponential part of the dephasing rate of recent two-pulse photon-echo experiments $\left[{ }^{40}\right]$. This part of the dephasing rate is attributed to the relaxation due to intrinsic glass processes. One such process has been taken into account in our calculation, another might be the result of fast spectral diffusion. Because this type of experiment avoids the time lag between the burning of the hole and the measurement of the hole width, it is extremely helpful for comparisons of homogeneous linewidth calculations with experimental values. Finally, it should be noted that from recent measurements down to $0.04 \mathrm{~K}\left[{ }^{41}\right]$ a transition from the $T^{1.3}$ to the $T^{2.5}$ behaviour of the linewidth has been derived as predicted by our calculations.

\section{Acknowledgement}

This work was in part supported by the Deutsche Forschungsgemeinschaft.

\section{REFERENCES}

1. Castro, G., Haarer, D., Macfarlane, R. M., Trommsdorf, H. P. U. S. Patent № 4 101976 (1978).

2. Anderson, P. W., Halperin, B. I., Varma, C. M. Phil. Mag., 25, 1 (1972).

3. Phillips, W. A. J. Low Temp. Phys, 7, 351 (1972).

4. Selzer, P. M., Huber, D. L., Hamilton, D. S., Yen, W. M., Weber, M. J. Phys. Rev, Lett., 36, 813 (1976).

5. Hegarty, J., Yen, W. M. Phys. Rev. Lett., 43, 1126 (1979).

6. Walsh, C. A., Berg, M., Narasimhan, L. R., Littau, Karl A., Fayer, M. D. Chem. Phys, Lett., 134, 268 (1987).

7. Friedrich, J., Haarer, D. In: Optical Spectroscopy of Glasses (ed. I. Zschokke). Reidel, 1986.

8. Jankoviak, R., Bässler, H., Silbey, R. Chem. Phys. Lett., 125, 139 (1986)

9. van der Berg, R., Völker, S. Chem. Phys. Lett., 127, 525 (1986)

10. Feary, B. L., Carter, T. P., Small, G. J. Chem. Phys,, 101, 279 (1986).

11. Burkhalter, F. A., Suter, G. W., Wild, U. P., Samoilenko, V. D., Rasumova, N. V. Personov, R. I. J. Chem. Phys., 94, 483 (1983).

12. Aubert, C., Fünfschilling, J., Zschokke-Gränacher, I., Wildmann, T. A., Siebrand, W Chem. Phys. Lett., 122, 465 (1985).

13. Bogner, U., Schätz, P., Maier, M. Chem. Phys. Lett., 102, 267 (1983).

14. Gorokhovskii, A. A., Korrovits, V. H., Pal'm, V. V., Trummal, M. A. JETP Lett., 42, 407 (1985).

15. Samoilenko, V. D., Razumova, N. V., Personov, R. I. Opt. Spectrosc., 52, 346 (1982).

16. Macfarlane, R. M., Shelby, R. M. Opt. Commun., 45, 46 (1983).

17. Molenkamp, L. W., Wiersma, D. A. J. Chem. Phys., 83, 1 (1985).

18. Hegarty, J., Broer, M. M., Golding, B., Simpson, J. R., MacChesney, J. B. Phys. Rev. Lett., 51, 2033 (1983).

19. Walsh, C. A., Berg, M., Narasimhan, L. R., Fayer, M. D. Chem. Phys. Lett., 130, 6 (1986).

20. Reinecke, T. L. Solid State Commun,, 32, 1103 (1979).

21. Hunklinger, S., Schmidt, M. Z. Phys, B - Condensed Matter, 54, 93 (1984).

22. Krivoglaz, M. A. Sov. Phys. JETP, 61, 1284 (1985).

23. Huber, D. L. Preprint.

24. Black, J. L., Halperin, B. I. Phys. Rev. B, 16, 2879 (1977)

25. Small, G. J. In: Spectroscopy and Excitation Dynamics of Condensed Molecular Systems (eds V. M. Agranovich, R. M. Hochstrasser). Amsterdam, North Holland, 1985,515 .

26. Lyo, S. K., Orbach, R. Phys. Rev. B, 22, 4223 (1980).

27. Lyo, S. K. Phys. Rev. Lett., 48, 688 (1982).

28. Reineker, P., Morawitz, H. Chem. Phys. Lett, 86, 359 (1982)

29. Reineker, P., Morawitz, H., Kassner, K. Phys. Rev. B, 29, 4546 (1984).

30. Kassner, K., Reineker, P. Chem. Phys., 106, 345 and 371 (1986); Phys. Rev. B, 35, 828 (1987). 
31. Morawitz, H., Reineker, P. Solid State Commun., 42, 609 (1982).

32. Lyo, S. K., Orbach, R. Phys. Rev. B. 29, 2300 (1984).

33. Jackson, B., Silbey, R. Chem. Phys. Lett., 99, 331 (1984)

34. Osad'ko I. S. JETP Lett., 33, 626 (1981).

35. Huber, D. L. J. Non-Cryst. Sol., 51, 241 (1982).

36. Osadko, I. S., Shtygashev, A. A. J. Luminescence, 36, 315 (1987).

37. Kassner, K. Ph. D. Thesis, University of Ulm, 1985.

38. Reineker, P., Kassner. K., Morawitz, H. In: Conference Proceedings of the VW Symposium, Mittelberg, 16.-21. 9. 84, on Photoreaktive Festkörper (ed. H. Sixl). Karlsruhe, Wahl-Verlag, 1984, 65.

39. Thijssen, H. P. H., van der Berg, R. E., Völker, S. Chem. Phys. Lett., 97, 295 (1983); ibid., 103, 23 (1983);

40. Walsh, C. A., Berg, M., Narasimhan, L. R., Fayer, M. D. J. Chem. Phys., 86, 77 (1987).

41. Gorokhcuskii, A. A., Korrovits, V. H., Pal'm, V. V., Trummal, M. A. Abstracts of the Symposium «Modern Methods of Laser Spectroscopy of Molecules on LowTemperature Media». Tallinn, 1987.

University of Ulm, FRG

Received

Institute for Solid State Research of Yülich, FRG

Sept. 21,1987

\section{P. REINEKER, K. KASSNER}

\section{OPTILISTE LISANDIOLEKUTE DEFASEERUMINE KLAASIDES: MADALA TEMPERATUURI REZIIM}

Optiliste lisandite defaseerumist amorfsetes maatriksites on käsitletud mikroskoopilise mudeli raames. Korrastamata maatriksi dünaamikat on kirjeldatud foononite ja klaasidele iseloomulike kahenivooliste süsteemide abil. On arvestatud kahenivooliste süsteemide interaktsiooni lisandiga ja maatriksi-termostaadi võnkumistega. Joone kuju on arvutatud lineaarse teooria lähenduses vastastikmōju korral nii ühe kui mitme kahenivoolise süsteemiga. On leitud, et eksperimentaalselt jälgitud joone laiust saab seletada üksnes mitme kahenivoolise süsteemi koosmõjuga. Väga madalal temperatuuril suureneb joone laius vōrdeliselt $T^{2,5}$ kõrgema temperatuuri piirkonnas $T^{1,3}$, mis on kooskōlas katsetulemustega. Viimase piirkonna optilise defaseerumiskiiruse temperatuurilise sõltuvuse kohta pakutakse mitmeid seletusi kooskõlas teooria üldise matemaatilise struktuuriga.

\section{П. РЕИНЕКЕР, K. KACCHEP}

\section{ДЕФАЗИРОВКА ОПТИЧЕСКИХ СОСТОЯНИИ ПРИМЕСИ В СТЕКЛАХ: РЕЖИМ НИЗКИХ ТЕМПЕРАТУР}

Дефазировка оптиंческих состояний примесей в аморфных матрицах рассмотрена в рамках микроскопической модели. Динамика неупорядоченной матрицы описывается фононами и ансамблем двухуровневых систем (ДУС), являющимися характерными степенями свободы стекол. ДУС взаимодействуют как с примесью, так и с колебаниями матрицы, которые рассматриваются как тепловой резервуар. По теории линейного отклика получено выражение для формы линии как в случае одной дУС, так и большого числа ДУС, взаимодействующих с примесью. Найдено, что, экспериментально наблюдаемые ширины могут быть объяснены только в случае, если реализуется последняя ситуация. При очень низких температурах ширина линии растет как $T^{2,5}$, в последующем температурном интервале - как $T^{1,3}$, что находится в соответствии с экспериментальными результатами. Для второй температурной области предложено несколько объяснений температурной зависимости скорости оптической дефазировки, котөрые согласуются с математической структурой теории. 